\title{
Plasticity of Hypothalamic Dopamine Neurons during Lactation Results in Dissociation of Electrical Activity and Release
}

\author{
Nicola Romanò, ${ }^{1,2,3}$ Siew H. Yip, ${ }^{4}$ David J. Hodson, ${ }^{1,2,3,5}$ Anne Guillou, ${ }^{1,2,3}$ Sébastien Parnaudeau, ${ }^{6,8}$ Siobhan Kirk, ${ }^{4}$ \\ François Tronche, ${ }^{6,7,8}$ Xavier Bonnefont, ${ }^{1,2,3}$ Paul Le Tissier, ${ }^{9}$ Stephen J. Bunn, ${ }^{4}$ Dave R. Grattan, ${ }^{4}$ Patrice Mollard, ${ }^{1,2,3}$ \\ and Agnès $\mathbf{0 .}$ Martin ${ }^{1,2,3}$ \\ ${ }^{1}$ CNRS, UMR-5203, Institut de Génomique Fonctionnelle, F-34000 Montpellier, France, ${ }^{2}$ INSERM, U661, F-34000 Montpellier, France, ${ }^{3}$ Universités de \\ Montpellier 1 \& 2, UMR-5203, F-34000 Montpellier, France, ${ }^{4}$ Department of Anatomy, University of Otago, Dunedin 9054, New Zealand, ${ }^{5}$ Department of \\ Medicine, Section of Cell Biology, Division of Diabetes Endocrinology and Metabolism, Imperial College London, London SW7 2AZ, United Kingdom, \\ ${ }^{6}$ National Center of Scientific Research, Coeducational Research Unit 7224, Molecular Genetics, Neurophysiology, and Behavior, F-75005 Paris, France, \\ ${ }^{7}$ Pierre et Marie Curie University, F-75005, Paris, France, ${ }^{8}$ National Institute of Health and Medical Research, Unit 952, F-75005 Paris, France, and ${ }^{9}$ Neural \\ Development Unit, Institute of Child Health, London WC1E 6BT, United Kingdom
}

Tuberoinfundibular dopamine (TIDA) neurons are the central regulators of prolactin (PRL) secretion. Their extensive functional plasticity allows a change from low PRL secretion in the non-pregnant state to the condition of hyperprolactinemia that characterizes lactation. To allow this rise in PRL, TIDA neurons are thought to become unresponsive to PRL at lactation and functionally silenced. Here we show that, contrary to expectations, the electrical properties of the system were not modified during lactation and that the neurons remained electrically responsive to a PRL stimulus, with PRL inducing an acute increase in their firing rate during lactation that was identical to that seen in non-pregnant mice. Furthermore, we show a long-term organization of TIDA neuron electrical activity with an harmonization of their firing rates, which remains intact during lactation. However, PRL-induced secretion of dopamine (DA) at the median eminence was strongly blunted during lactation, at least in part attributable to lack of phosphorylation of tyrosine hydroxylase, the key enzyme involved in DA synthesis. We therefore conclude that lactation, rather than involving electrical silencing of TIDA neurons, represents a condition of decoupling between electrical activity at the cell body and DA secretion at the median eminence.

\section{Introduction}

Plasticity is a fundamental property that allows neuronal networks to adapt to environmental changes. In the adult, it has been related to physiological and pathological conditions, such as formation of memories, response to trauma, or neurodegeneration (Kreitzer and Malenka, 2007; Shen et al., 2008; Surmeier et al., 2009). Because of their role in maintaining the homeostasis of the body, neuroendocrine cells provide an ideal opportunity to study

Received Sept. 14, 2012; revised Jan. 9, 2013; accepted Jan. 14, 2013.

Author contributions: N.R., S.J.B., D.R.G.,P.M., and A.O.M. designed research; N.R., S.H.Y., D.J.H., A.G., S.P., F.T. P.L.T., and A.O.M. performed research; S.K. contributed unpublished reagents/analytic tools; N.R., S.H.Y., and A.O.M. analyzed data; N.R., X.B., and A.O.M. wrote the paper.

This work was funded by National Agency of Research Grant DAT-NET 2007, National Institute of Health and Medical Research, National Center of Scientific Research, Montpellier Universities 1 and 2, Foundation for Medical Research, National Network of Génopoles, Federative Research Institutes No. 3, and Languedoc-Roussillon Region. We thank Pierre Fontanaud and François Molin o for the discussion on data analysis methods, Pierre François Méry for discussion on this manuscript, the staff of the animal house at the Institute of Human Genetics for the daily care of animals, and Prof. David Sultzer and Prof. Dalimor Sames for the kind gift of FFN-511. The antibodies for PRL radioimmunoassay were supplied by Dr. A. F. Parlow and National Institute of Diabetes and Digestive and Kidney Diseases National Hormone and Peptide Program (University of California, Los Angeles, Los Angeles, CA). Confocal microscopy has been performed using the facilities of Regional Center of Cell Imagery (Montpellier, France).

Correspondence should be addressed to Agnès 0 . Martin, CNRS, UMR-5203, Institut de Génomique Fonctionnelle, F-34000 Montpellier, France. E-mail: agnes.martin@igf.cnrs.fr.

D0I:10.1523/JNEUROSCI.4415-12.2013

Copyright $\odot 2013$ the authors $\quad 0270-6474 / 13 / 334424-10 \$ 15.00 / 0$ how electrical activity affects physiological functions and, conversely, how changes in physiological function modulate neuronal activity. Several populations of neuroendocrine cells have been studied, offering an impressive picture of their diversity and plasticity (Herbison, 2006; Baccam et al., 2007; Krsmanovic et al., 2010; Leng et al., 2010). We focused our attention on the tuberoinfundibular dopamine (TIDA) neurons of the arcuate nucleus (Arc), for their versatility over the course of the reproductive cycle. TIDA neurons project to the median eminence $(\mathrm{ME})$, in which they secrete dopamine (DA) onto the fenestrated blood vessels of the pituitary portal system (Björklund et al., 1973; Reymond and Porter, 1985), providing the major inhibitory input to prolactin (PRL) secretion. The pulsatility of PRL release relies on the inhibitory tone of DA: the increased secretion of PRL required during lactation involves a disinhibition through suppression of DA secretion (Moore, 1987; Arbogast and Voogt, 1996). The resultant hyperprolactinemia allows mammary gland development and milk production, together with a wide range of adaptive responses in the CNS (Bridges et al., 1985; Lucas et al., 1998; Freeman et al., 2000; Shingo et al., 2003; Grattan and Kokay, 2008; Larsen and Grattan, 2010). PRL regulates its own secretion by activating TIDA neurons (MacLeod et al., 1970; BenJonathan, 1985) through PRL receptors (PRL-Rs) (Lerant et al., 
2001; Kokay and Grattan, 2005). Thereby, rising levels of PRL increase DA secretion at the ME, subsequently inhibiting additional PRL secretion. Although this feedback loop can explain the PRL output in virgin animals (Reymond and Porter, 1985; BoleFeysot et al., 1998; Freeman et al., 2000), it fails to explain the long-term physiological lactational hyperprolactinemia. For this, DA secretion must be suppressed in the presence of an ongoing PRL stimulus (Demarest et al., 1983; Arbogast and Voogt, 1996). TIDA neurons are described as "inactive" during this period, with reduced activity [decreased Arc expression of tyrosine hydroxylase (TH) mRNA and protein (Wang et al., 1993; Li et al., 1999), DA turnover at the ME (Andrews, 2005), and secretion of DA (Ben-Jonathan, 1980)]. The mechanisms by which this "silencing" is achieved remain unknown.

We hypothesized that the electrophysiological characteristics of TIDA would change during different physiological states to reflect their changed functionality and that the response to PRL would be suppressed in states in which elevated PRL was required. We analyzed three different physiological situations: (1) PRL basal secretion (virgin females); (2) physiological hyperprolactinemia (lactating females); and (3) one of no gross change in the PRL secretion pattern (males). This study examined how the physiological state affects the functionality of the TIDA network in terms of electrical activity and output, at the single-cell and population levels.

\section{Materials and Methods}

Animals. DAT-iCre animals (Turiault et al., 2007) were crossed with the ROSA26-eYFP reporter line (Srinivas et al., 2001) to identify DA transporter (DAT)-expressing cells. In the Arc, an almost complete colocalization between TH and YFP was seen. For virgin female animals, the stage of estrous cycle was monitored by means of vaginal smears. Because none of the electrophysiological parameters that was analyzed correlated with the specific day of the cycle, the data were pooled together. All animal studies complied with the animal welfare guidelines of the European Community (Agreement 34.128) or were approved by the Animal Ethics Committee of the University of Otago (Dunedin, New Zealand).

Brain slice preparation. Coronal brain slices were used for electrophysiology and DA secretion experiments. Adult ( $>50 \mathrm{~d}$ old) DAT-iCre $\times$ ROSA26-eYFP mice were killed by rapid decapitation, between 10:00 A.M. and 12:00 P.M., after isoflurane anesthesia. The brain was quickly removed and placed in ice-cold artificial CSF (ACSF) containing the following (in mM): $118 \mathrm{NaCl}, 3 \mathrm{KCl}, 11 \mathrm{D}$-glucose, 10 HEPES, 25 $\mathrm{NaHCO}_{3}, 6 \mathrm{MgCl}_{2}$, and $0.5 \mathrm{CaCl}_{2} 0.5$ (osmolarity between 295 and 305 mOsm, pH 7.2 when gassed with $5 \% \mathrm{CO}_{2}$ and $95 \% \mathrm{O}_{2}$ ). The brain was then glued to the stage of a vibratome, and $200-\mu \mathrm{m}$-thick coronal sections were cut. The slices were transferred at $32^{\circ} \mathrm{C}$ into oxygenated recording ACSF, with the same composition as above but containing 2.4 $\mathrm{mm} \mathrm{MgCl}$ and $2.5 \mathrm{mM} \mathrm{CaCl}_{2}$. This same solution was subsequently used for the recordings.

Recordings of electrical activity. Slices were immobilized with a nylon grid in a submersion chamber on the stage of an upright microscope (Axioskop FS2; Carl Zeiss) and superfused with recording solution. Borosilicate glass pipettes $(6-8 \mathrm{M} \Omega$ ) were backfilled with recording ACSF and connected to the head stage of an EPC-10 amplifier (HEKA) to acquire and store data using Patchmaster $2 \times 42$ software. Neuronal activity was recorded in voltage-clamp mode, in a loose-patch configuration (30-150 M $\Omega$ seal resistance). Ovine PRL (500 ng/ml; Sigma-Aldrich), which was shown previously to bind to the murine PRL-R, was bath applied.

Amperometric measurement of DA secretion. Carbon fiber microelectrodes were fabricated as described previously (Pike et al., 2009) using 30- $\mu \mathrm{m}$-diameter carbon fibers (World Precision Instruments). The capillaries were backfilled with a $2 \mathrm{M} \mathrm{KCl}$ solution, conditioned in a $150 \mathrm{~mm}$ $\mathrm{NaCl}, \mathrm{pH} 9.5$, solution at $1.2 \mathrm{~V}$ for $20 \mathrm{~min}$ before being connected to the head stage of an HEKA EPC10 amplifier. Microelectrodes were then tested in a chamber during perfusion with increasing concentrations of DA. Electrodes that did not respond to DA were discarded. The microelectrode was then lowered onto the slice at the level of the external zone of the ME so that it was in close contact with the DAergic terminals and held at $700 \mathrm{mV}$ to record DA secretion. Several negative controls were performed: the microelectrode, held at $700 \mathrm{mV}$, was lowered on nonDAergic or low DA-expressing brain regions (e.g., cortex) or at the level of the ME but not touching the tissue. In addition, recordings were performed at the ME using a holding potential of $0 \mathrm{mV}$. All of these negative controls resulted in no detectable current.

It is important to note that, although DA will promptly oxidate at the carbon fiber tip when held at $700 \mathrm{mV}$, this does not exclude that other oxidable molecules could be detected. However, in the specific case of this study, we consider it unlikely that adrenaline and noradrenaline are present because they are not secreted at the ME (Ben-Jonathan et al., 1977). The DA metabolite dihydroxyphenylacetic acid is surely detected along with DA, but its levels in the portal blood are $\sim 10 \%$ of those of DA (Anderson et al., 2006). Finally, another molecule that can contaminate the signal is ascorbic acid (Gonon et al., 1981), but we currently have no indication that it is cosecreted by TIDA neurons or that it is present at the level of the ME.

Immunohistochemistry. After pentobarbital-induced anesthesia, brains were fixed by intracardiac perfusion with $4 \%$ paraformaldehyde in $0.1 \mathrm{M}$ phosphate buffer, $\mathrm{pH} 7$, and left overnight in the same fixative. Floating sections were incubated for $48 \mathrm{~h}$ at $4^{\circ} \mathrm{C}$ with primary antibodies diluted in PBS with $1 \%$ BSA and $0.1 \%$ Triton X-100 in PBS and then $4 \mathrm{~h}$ at $4^{\circ} \mathrm{C}$ with the corresponding secondary antibodies conjugated with horseradish peroxidase. Quenching for endogenous peroxidases was performed by incubation in a $10 \% \mathrm{H}_{2} \mathrm{O}_{2}$ and $10 \%$ methanol PBS solution for $20 \mathrm{~min}$ before immunostaining. The amplification kit VECTASTAIN Elite ABC system (Vector Laboratories) was used according to the protocol of the manufacturer. Each experiment included negative controls using secondary antibody alone to test for nonspecific staining. Primary antibodies were chicken anti-TH (Abcam) and rabbit anti-phospho-TH at Ser ${ }^{40}$ (Zymed Laboratories).

Western blot analysis. Virgin and lactating mice were killed by cervical dislocation. Brains were immediately frozen, and 300- $\mu$ m-thick coronal brain slices containing the Arc were cut on a cryostat at $-20^{\circ} \mathrm{C}$. The Arc and ME were micropunched from each section, with a single $500-\mu \mathrm{m}-$ diameter punch centered on the third ventricle. Punches were lysed for protein extraction, and equal amounts of protein from the samples were loaded onto a $7.5 \%$ polyacrylamide gel and subsequently transferred to a nitrocellulose membrane. Membranes were probed with rabbit antiphospho-TH at $\operatorname{Ser}^{40}$ (1:2000; Zymed Laboratories) and reprobed with mouse anti-TH (1:12,000; Millipore) and mouse anti- $\beta$-actin (1:12,000; Abcam Sapphire Bioscience). Relative levels of the proteins were determined using densitometric image analysis (Quantity One 1-D Analysis Software; Bio-Rad).

FFN-511 experiments. Brain slices containing the ME were obtained and incubated in a $10 \mu \mathrm{M}$ solution of FFN-511 (Gubernator et al., 2009) in ACSF for $60 \mathrm{~min}$ at $37^{\circ} \mathrm{C}$ in $5 \% \mathrm{CO}_{2} / 95 \% \mathrm{O}_{2}$ (FFN-511 was a kind gift from Prof. D. Sames and Prof. D. Sulzer, Columbia University, New York, NY). FFN-511 is a fluorescent DA analog. It is taken up by vesicular monoamine transporter 2 (VMAT2) with the same kinetic and affinity as DA and subsequently packaged into DA vesicles (see Fig. $5 A$; a complete description of FFN-511 can be found in the study by Gubernator et al., 2009). For these experiments, $\sim 1$-mm-thick horizontal slices containing the ME and Arc were used. This cut allowed better $z$-stability when imaging terminals and had the advantage of showing the whole external surface of the ME. Slices were imaged using a multi-beam two-photon system (Trimscope; LaVision Biotec). A $300 \times 300 \mu \mathrm{m}$ area of the ME was imaged in 64-beam mode using a low-magnification waterimmersion objective (20×, numerical aperture 0.95 Plan Fluorite; Olympus). Excitation was performed at $760 \mathrm{~nm}$ with a femtosecond pulsed laser (titamium:sapphire; Coherent), and emission was filtered at 468 $552 \mathrm{~nm}$. Images were captured by a 16-bit EM-CCD camera (Andor). A $z$-stack of the ME area (35 2- $\mu$ m-thick $z$-planes) was taken every $20 \mathrm{~s}$ for $30 \mathrm{~min}$. Either ACSF or a $500 \mathrm{ng} / \mathrm{ml}$ PRL solution in ACSF was perfused 
in the recording chamber. The threedimensional (3D) volumes were then analyzed in Imaris (Bitplane). Semiautomatic particle detection and $3 \mathrm{D}$ tracking was performed, and the median pixel intensities of the regions were calculated over time.

Response to DA antagonists. Trunk blood was collected from virgin or lactating animals treated with an intraperitoneal injection of vehicle ( $1 \% \mathrm{DMSO}$ in $0.9 \% \mathrm{NaCl}$ ) or a DA receptor $\left(\mathrm{D}_{2}\right)$ antagonist ( $n=4$ per group). Plasma PRL levels were measured by radioimmunoassay, using reagents from The National Institute of Diabetes and Digestive and Kidney Diseases, as described previously (McGuinness et al., 2003).

The $\mathrm{D}_{2}$ receptor antagonists used included $0.1 \mathrm{mg} / \mathrm{kg}$ haloperidol (Abcam) and $20 \mathrm{mg} / \mathrm{kg}$ domperidone (Abcam).

Statistical analyses. Patchmaster files were imported in Igor Pro (Wavemetrics) for the analysis of interspike intervals (ISIs), and action currents were detected using a threshold method. The times of action currents were then exported to a text file to be analyzed with custom-written routines in $\mathrm{R}$ ( $\mathrm{R}$ Development Core Team, 2010), used to detect the firing frequency and the shape of the $\log _{10}$ (ISI) histogram. Clustering analysis of the $\log _{10}$ (ISI) histograms was performed in $\mathrm{R}$ using a method similar to that used previously (Nowak et al., 2003). Briefly, the $\log _{10}$ (ISI) histogram was calculated for each recording, and a bimodal distribution was fitted using a vector generalized linear model. A number of statistical descriptors for the distribution were then obtained to be used as classifiers for the clustering: mean, median, skewness, kurtosis, and interquartile range of the $\log$ (ISI) distribution. Along with these, the mean firing frequency, the local variation coefficient Lv (Shinomoto et al., 2003), and a "binormality index" were also used as classifiers. The binormality index was calculated as $\left(\mu_{1}-\mu_{2}\right) /\left(\sigma_{1}-\sigma_{2}\right)$, where $\mu_{1}$ and $\mu_{2}$ are the mean of the two modes of the distribution, and $\sigma_{1}$ and $\sigma_{2}$ are the corresponding SDs; when a bimodal distribution could not be fitted (e.g., for strongly unimodal distributions), the binormality was set to 0 . The classifiers were then standardized as $z$-scores (mean $=0, \mathrm{SD}=1$ ), and hierarchical clustering was performed using Euclidean distances and a Ward clustering method.

To determine the period of oscillations in the firing frequency, the fast Fourier transform (FFT) of the autocorrelation function (ACF) of the firing rate was analyzed. To determine significant frequencies in the FFT, 95\% confidence limits were determined using a Monte Carlo method: the ACF/FFT analysis was repeated 1000 times on signals generated by randomly swapping the ISIs. The frequencies showing an FFT value in the original signal that was greater than that of $95 \%$ of these random swaps were considered significant. The same method of analysis was used to calculate confidence limits for the analysis of simultaneous patch and amperometry or double-patch experiments.

ANOVA of generalized linear models, $t$ test, and Fisher's exact test were used when appropriate to compare the different experimental groups as indicated in the text and figure legends.

\section{Results}

\section{TIDA neurons continue to respond to PRL at lactation}

We performed cell-attached electrical recordings of identified TIDA neurons to assess the effects of PRL on their firing rate and pattern. After at least $15 \mathrm{~min}$ of recording of spontaneous activity, slices were treated for $15 \mathrm{~min}$ with $500 \mathrm{ng} / \mathrm{ml} \mathrm{PRL}$, followed by 15-45 min of washout period. Treatment with PRL induced a reversible increase in firing rate in the majority of TIDA neurons, independently of sex or reproductive state ( $n=13$ of 20 males, 9 of 16 virgin females, 10 of 13 lactating females; Fig. $1 A-C$ ). The increase in firing rate was heterogeneous, ranging from $120 \%$ to $>1000 \%$ increase from the initial firing rate. No statistical difference was found between the percentage of responsive cells in the different experimental groups ( $p=0.55$, Fisher's exact test; Fig. $1 C$, top) or between the maximum PRL-induced increase in firing rate $(p=0.65$, one-way ANOVA; Fig. $1 C$, bottom $)$.

\section{Decrease in DA secretion during lactation}

The effects of lactation on DA secretion at the ME were assessed through in situ constant voltage amperometry. As a result of activating most of the TIDA population, bath application of 500 $\mathrm{ng} / \mathrm{ml}$ PRL induced DA secretion in $70-80 \%$ brain slices from virgin males or females (males, $n=9$ of 13 slices from 7 animals; females, $n=8$ of 10 slices from 5 animals). In contrast, although PRL continued to increase the firing rate of neurons from lactating animals (Fig. 1A), no DA secretion could be detected by amperometry in slices from lactating females ( 0 of 10 slices from 5 animals; Fig. 1D). Similar results were obtained with a nonspecific depolarizing stimulus $(30 \mathrm{~mm} \mathrm{KCl})$, which was able to induce a strong release of DA only in slices from virgin animals $(n=$ 11 of 12 responding slices from 7 virgins, 0 of 7 responding slices, from 4 lactating females; Fig. 1D). To further confirm these results, PRL levels were measured after treatment of virgin and lactating females with the $\mathrm{D}_{2}$ receptor antagonists haloperidol $(0.1 \mathrm{mg} / \mathrm{kg})$ or domperidone $(20 \mathrm{mg} / \mathrm{kg})$ to remove endogenous DAergic tone on lactotrophs. Domperidone does not cross the blood-brain barrier and was used to exclude confounding effects of treatment on the CNS. Although a strong increase $(>1000 \%)$ 

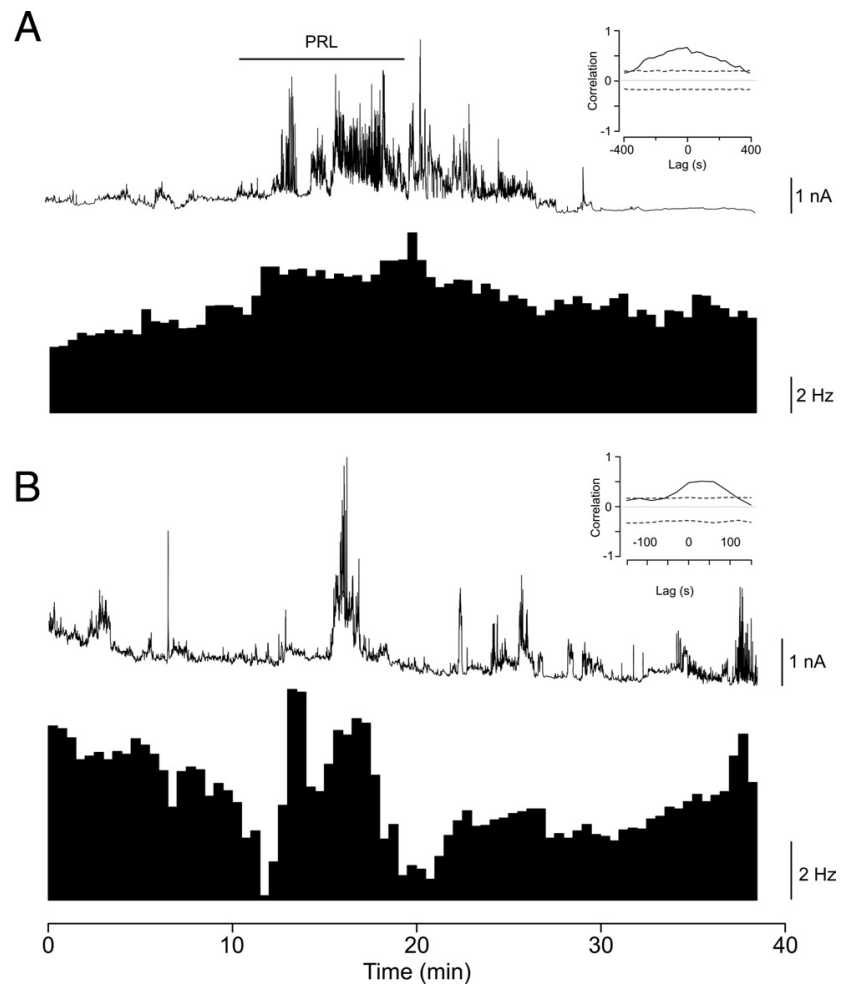

Figure 2. Coordinated secretion and electrical activity in TIDA neurons. $A$, Representative simultaneous amperometric and patch-clamp recording of the PRL-induced activity of a TIDA neuron from a virgin female. Top trace shows the amperometric signal, and bottom histogram shows the firing rate of the neuron in $30 \mathrm{~s}$ bins. Black bar indicates bath application of PRL (500 $\mathrm{ng} / \mathrm{ml}$ for $10 \mathrm{~min}$ ). A strong increase in the firing rate is visible a few minutes after the PRL stimulus, coinciding with an increase in DA secretion at the ME. Inset shows the crosscorrelation function of the two traces, with a maximum correlation of $0.65 \mathrm{at}$ lag $0 \mathrm{~s}$. Dotted lines represent $95 \%$ confidence limits. B, Simultaneous amperometric and cell-attached voltageclamp recording of the spontaneous activity of an identified TIDA neuron from a virgin female DAT-iCre $\times$ ROSA26-eYFP mouse. Top trace shows the amperometric signal, and bottom histogram shows the firing rate of the neuron in $30 \mathrm{~s}$ bins. Spontaneous episodes of secretion coincide with local increases in firing rate. Inset shows the cross-correlation function of the two traces, with a maximum correlation of 0.51 at lag 30 s. Dotted lines represent $95 \%$ confidence limits.

in plasma PRL levels was detected in virgin animals, only a small and nonsignificant rise was observed in lactating animals (Fig. $1 E$, $n=4$ per group), confirming the presence of low endogenous DA tone during this physiological state.

\section{The firing of TIDA neurons correlates with DA secretion in virgin animals}

To describe the relationship between electrical activity and DA secretion from TIDA neurons, we performed simultaneous amperometry and cell-attached recordings in brain slices.

DA secretion was recorded in brain slices subjected to a $15 \mathrm{~min}$ treatment with $500 \mathrm{ng} / \mathrm{ml} \mathrm{PRL}$. When DA secretion was monitored together with the electrical activity of randomly selected TIDA neurons, a strong correlation was seen between the two measurements in response to the PRL treatment (Fig. $2 A, n=4$ of 5 responding slices).

Furthermore, we observed spontaneous secretion of DA in $\sim 50 \%$ of the slices from virgin females. During simultaneous recordings on slices in which we could measure spontaneous events of DA secretion, we found that spontaneous changes in firing rate of a randomly chosen TIDA neuron positively correlated with episodes of DA release (Fig. $2 B$, average \pm SEM corre- lation value $=0.44 \pm 0.06, n=5$ of 15 cells from 15 slices). The spontaneous periods of elevated frequency of firing were very similar to the increases of firing induced by PRL application, suggesting that these periods of elevated firing rates were involved in the generation of DA secretion episodes in virgin animals. Because no DA secretion could be detected in slices from lactating animals (Fig. $1 D$, right), it was not possible to determine any correlation with firing frequency in this state.

It is important to emphasize that these experiments measured spontaneous electrical activity of a randomly selected cell body and DA secretion from numerous terminals in the ME, likely originating from several different TIDA neurons (i.e., not the recorded neuron). The observed positive correlation between these two measures therefore suggests that a global harmonization of electrical activities exists in the TIDA neuronal population. As such, the generation of episodic DA secretion may be a result of the presence of a functional network between TIDA neurons.

Lactation does not alter the harmonization of electrical activity within TIDA population

We examined the strength of communication between TIDA neighbors to test for the presence of a functional organization in their electrical activities, which could be at the origin of the pulsatile secretion of DA.

The electrical activity of the neighboring TIDA neuron was simultaneously assessed by dual patch-clamp recordings. To analyze correlation at the timescale of several minutes, we calculated the cross-correlation of the firing rates of the two cells. In virgin animals, it was possible to detect a significant correlation between the two firing rates with an average \pm SEM correlation value in the correlated pairs of $0.47 \pm 0.04$ (Fig. $3 A$; females, $n=2$ of 5 correlated couples from 4 animals; males, $n=3$ of 9 correlated couples, from 5 animals; the other couples did not show a significant correlation value). Long-term coordinated variations in spontaneous firing rate were detected in a similar proportion during lactation ( $n=3$ of 7 correlated couples from 4 animals; Fig. $3 A$, right). To confirm that this correlation was not accidental, we performed the same analysis on 20 pairs of randomly chosen neurons from independent recordings. Significant correlation was never found between these random pairs.

To determine whether electrical coupling was at the origin of this long-term coordination, we analyzed the instantaneous coordination at the level of the single action potential. We could not find any instantaneous synchronization between the recorded TIDA neurons (no pair showed peaks in the cross density histogram higher than the $95 \%$ confidence intervals; data not shown). Cells were chosen randomly in the zone delimited by the optical field of the microscope. Because of the relatively low density of the TIDA neurons, they were generally not directly apposed but generally separated by at least $50 \mu \mathrm{m}$.

\section{Lactation does not alter the electrical properties of TIDA population}

We determined the effect of lactation on the electrical properties of TIDA neurons. Analysis of the long-term changes in firing rate revealed no differences in the three experimental groups $(p>$ 0.05 , Fisher's exact test; $n=43$ males, 37 virgin females, 26 lactating females; Fig. $3 C, D$ ) concerning the periodicity and the percentage of cells showing transient firing rate changes. In all groups, $\sim 35 \%$ of cells showed a periodicity in the $3-5 \mathrm{mHz}$ range $(n=36$ of $106, \sim 200-300$ s period; Fig. $3 B-D)$. A small subset of 
these cells displayed strongly regular oscillations ( $n=5$ of 36 ; Fig. $3 B$, bottom). The rest of the cells did not show local changes (Fig. 3B, top). At a short timescale, different patterns of electrical firing were observed. Patterning of action potentials are key to the modulation of activity in neuronal networks (Bressloff and Coombes, 2005). We therefore investigated whether lactation could influence the electrical patterns of TIDA neurons. No statistically significant difference was found in the distribution of mean spontaneous firing rates of the cells in the three groups (virgin males, $n=43$; virgin females, $n=37$; lactating females, $n=26$; Fig. $4 A$ ). Analysis of ISIs was used to discriminate between different firing patterns. Three stereotypical types of the histograms of the $\log _{10}$ (ISI) could be discriminated: (1) unimodal, Gaussian (or skewed Gaussian) distribution, representing regularly firing cells; (2) bimodal distribution, representing bursting behavior; and (3) multimodal distribution, representing irregular firing (Fig. 4B). We used cluster analysis of the ISI to classify this heterogeneous neuronal population according to their firing properties (Nowak et al., 2003). Three groups of $\log _{10}$ (ISI) histograms could be discriminated, representing regularly firing ( $n=44$ of 106), bursting ( $n=$ 17 of 106), and irregularly firing $(n=45$ of 106) neurons (Fig. 4C). Approximately $40 \%$ of the cells in the three experimental groups displayed regular firing. Although a trend toward the decrease in the number of bursting cells was seen in lactating fe-

males, it was not statistically significant $(p>0.05$, Fisher's exact test; Fig. 4D).

To assess whether PRL could induce long-lasting changes in the electrical properties of the neurons, we compared the firing pattern of each cells before, during, and after PRL acute application. In $\sim 60 \%$ of the cells of each experimental group, the application of PRL did not induce changes in the firing pattern, and, overall, the effect of PRL on modification of the firing pattern failed to achieve statistical significance (Fig. 4E). No correlation was found between responsiveness to PRL and change in firing pattern.

\section{DA secretion apparatus is not affected during lactation}

Because both PRL and high $\mathrm{K}^{+}$failed to trigger DA secretion from the terminals of TIDA neurons, we explored whether their exocytotic apparatus was still functional. DA is physiologically packaged into secretory vesicles through the VMAT2 (Erickson and Varoqui, 2000), the activity of which therefore can modulate the rate of secretion of monoamines. Fluorescent DA analogs, such as FFN-511, are taken up by VMAT2 and subsequently packaged into DA vesicles (Fig. $5 A$; a complete description of FFN-511 can be found in the study by Gubernator et al., 2009). Secretion of FFN-511 can then be monitored through fluorescence imaging to determine the activity of the secretory apparatus even in the absence of DA. A significant increase in the rate of
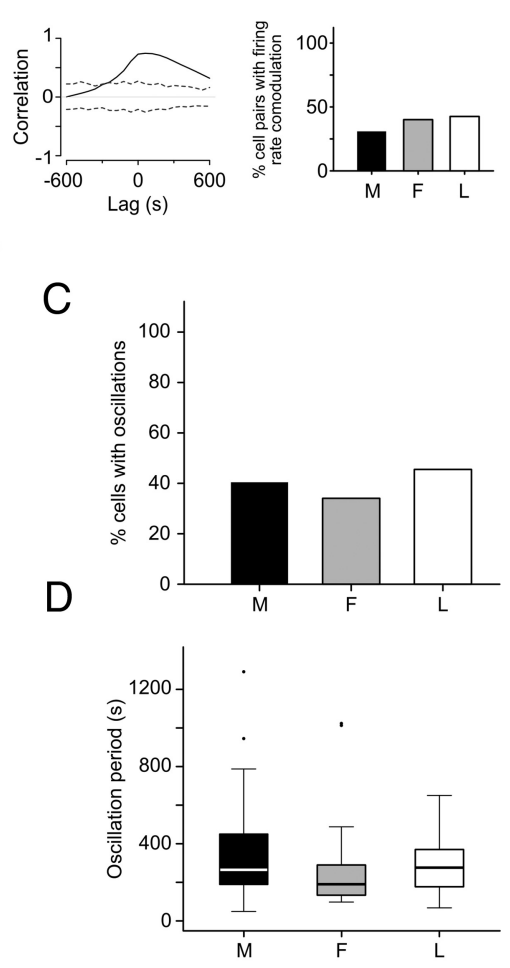

Figure 3. Long-term coordination between electrical activity in TIDA neurons. $\boldsymbol{A}$, Firing rate histograms of two simultaneously oscillations in firing rate in the three experimental groups. The groups are not statistically different $(p>0.05$

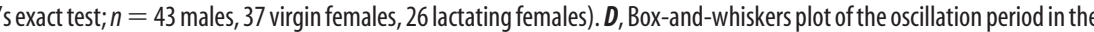
three groups, determined as the maximum of the FFT of the ACF, higher than the $95 \%$ confidence interval. Whiskers cover 1.5 times the interquartile range, and black dots represent outliers. M, Male; F, female; L, lactating.

fluorescence decay, indicative of increased secretion, was seen when slices from virgin females were incubated in PRL $(n=238$ terminals from 3 slices for controls, 407 terminals from 4 slices for PRL). In lactating animals, a similar result was obtained ( $n=$ 369 terminals from 3 slices for controls, 314 terminals from 4 slices for PRL), indicating that the exocytotic apparatus is still functional and responsive to PRL (Fig. $5 B, C$ ). PRL induced a decrease in the exponential decay half-time of the FFN-511 fluorescence intensity, which was not different between the two groups (Fig. $5 B, C$ ).

TH is a major player in the downregulation of DA at lactation To determine the cause of the diminished DA tone at lactation, we analyzed the expression and phosphorylation status of $\mathrm{TH}$, the rate-limiting enzyme for DA synthesis. Phosphorylation of Ser ${ }^{40}$ strongly enhances TH functionality, whereas phosphorylation at Ser ${ }^{19}$ does not impact TH catalytic activity (Zigmond et al., 1989; Dunkley et al., 2004). Analysis of the phosphorylation at the accessory site did not show any change in Ser ${ }^{19}$ phosphorylation (data not shown), whereas Ser ${ }^{40}$ phosphorylation was strongly decreased, particularly in the external zone of the ME during lactation (Fig. $5 D$, right). Western blot analysis revealed an overall decrease in the content of $\mathrm{Ser}^{40}$-phosphorylated $\mathrm{TH}$ in the arcuate/ME region, with no change in the total $\mathrm{TH}$ content during lactation (Fig. $5 E, F$ ). 
A

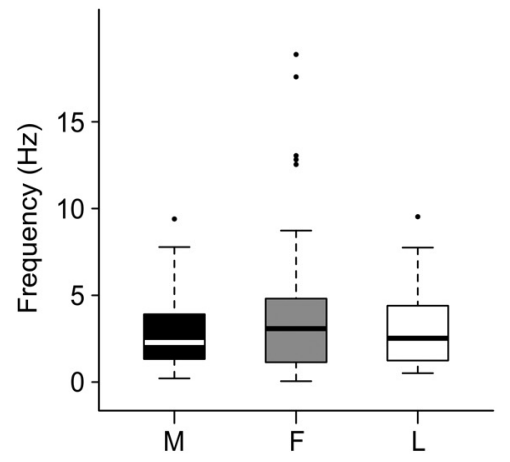

B
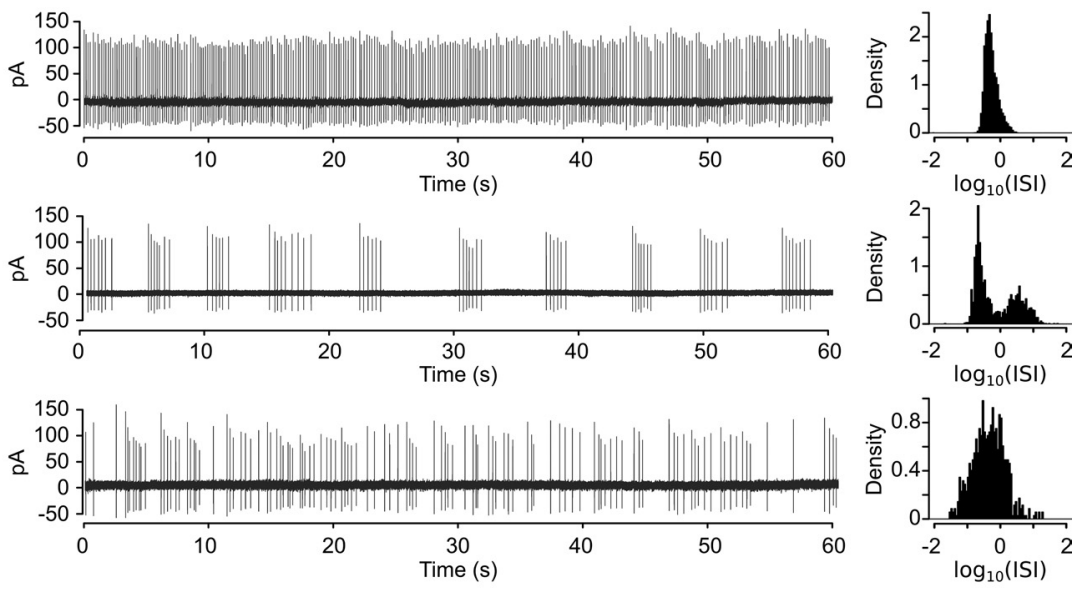

C

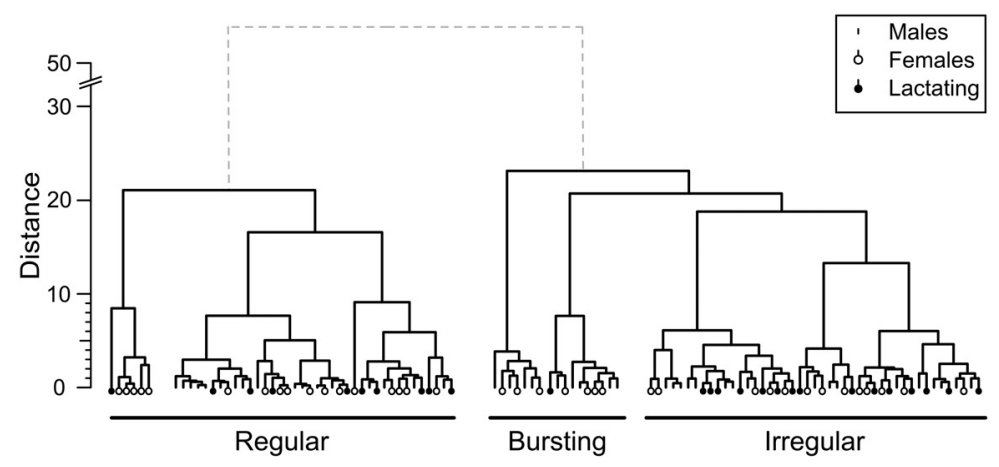

$\mathrm{E}$

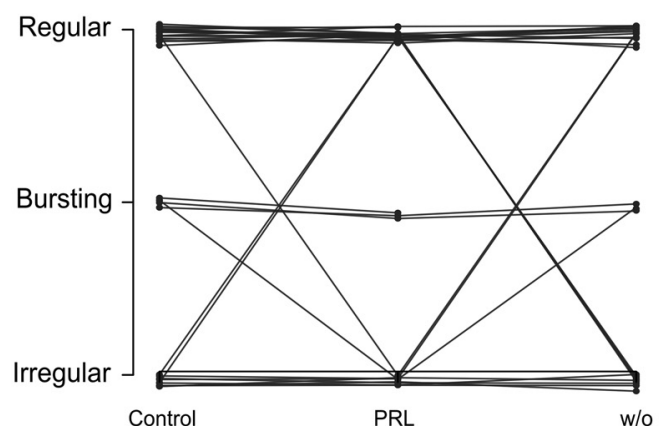

D

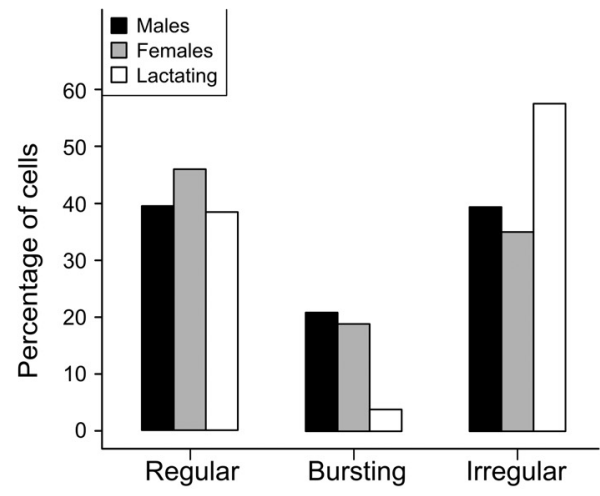

Figure 4. Lactation does not induce modification of TIDA neuron electrical properties. $A$, Average firing frequency of the cells recorded in the three experimental groups. Black dots represent outliers. The three groups are not statistically different ( $p=0.07$, one-way ANOVA). $\boldsymbol{B}$, Representative 1 min extracts of cell-attached voltage-clamp recordings from identified TIDA neurons. Recordings show regular (top), bursting (middle), and irregular (bottom) firing. Histograms of the $\log _{10}$ (ISI) of the traces on the left. The regular bursting cell (top) shows an almost normal distribution of the $\log _{10}(|S|)$; the bursting cell (middle) shows a clear bimodal distribution attributable to longer ISI between the bursts and shorter ISI in the bursts; the irregular cell (bottom) shows a multimodal distribution. C, Hierarchical clustering of the $\log _{10}(I S I)$ histograms for the spontaneous activity of the recorded cells. Each endpoint of the dendrogram represents one cell, indicated as a line for males, an open circle for virgin females, and a filled circle for lactating females. $\boldsymbol{D}$, Percentages of cells showing the three different firing patterns, divided by experimental group (groups are not statistically different, $p=0.2$, Fisher's exact test). $\boldsymbol{E}$, Left, Effect of PRL on the firing pattern of TIDA neurons treated with PRL. Each line represents a single cell; the pattern was determined during 15 min periods using a hierarchical clustering method. The majority of cells do not change their firing pattern (and thus they are represented by an horizontal line in the graph). Middle, Percentage of cells whose firing pattern was not modified by PRL application, grouped by firing pattern (groups are not statistically different, $p>0.05$, Fisher's exact test). Right, As in the middle, but cells are divided by experimental group (groups are not statistically different, $p>0.05$, Fisher's exact test). M, Male; F, female; L, lactating.

\section{Discussion}

To accommodate gestation and lactation, profound hormonal and physical changes happen in the lactotroph axis. It has been shown that, despite elevated PRL levels, DA output from TIDA neurons is markedly reduced during lactation. This observation led to the assumption that TIDA neurons become inactive and unresponsive to PRL (Ben-Jonathan, 1980; Demarest et al., 1983; Arbogast and Voogt, 1996; Andrews, 2005).Using an amperom- etry approach, we have confirmed this reduced DA release from TIDA during lactation. However, contrary to expectations, we show that the electrical properties of TIDA neurons, at the singlecell and network level, are maintained during this period of diminished DA output. Surprisingly, they continue to electrically respond to PRL at the cell-body level. In males and virgin females, increased firing was associated with DA secretion, but this was not observed during lactation. We therefore propose lactation as 
a state of uncoupling between firing and DA secretion in TIDA neurons rather than a period of electrical silencing.

\section{Relationship between firing and secretion in TIDA neurons}

The question of whether the activity at the cell body is a faithful measure of output is central in neuroendocrinology. Measuring hormonal output from neuroendocrine systems is technically challenging, especially in small animals, and electrophysiology or calcium imaging at the cell body have instead been used as an indirect measure (Leng et al., 1999; Terasawa et al., 1999). The anatomy of TIDA neurons is such that their cell bodies in the Arc can be studied in parallel to their terminals at the $\mathrm{ME}$ in the same coronal brain slice, allowing to simultaneously examine electrical activity and DA secretion from TIDA neurons.

Our data suggest a strong relationship between the firing frequency of single neurons and the output of a population of TIDA terminals in virgin animals. This is seen both in response to a PRL challenge and during spontaneous DA secretion. The correlation of the activity of a single neuron with the output of a proportion of the TIDA neuron population suggests that a degree of harmonization exists between the firing patterns of multiple neurons. In support of this, Lyons et al. (2010) have shown gap-junction-mediated synchronous membrane potential oscillations in TIDA.

Compared with a classical neuronneuron connection, the neuroendocrine neurohemal synapse has the peculiarity of secreting large amounts of material on a timescale of tens of minutes, or hours. Secretion of sufficient DA at the appropriate time by such a small neuronal population necessitates coordination of secretory events at the level of multiple neurons. We show that this happens through long-term modulation of firing rates rather than synchronization of single action potentials (Hong et al., 2012). This coordination was seen in only one-third of the neuronal pairs, maybe because of the sectioning of numerous afferents during slicing. Furthermore, multiple subpopulations of coordinated neurons may exist, and the electrophysiological approach is limited to the analysis of few cells at a time. The exact mechanisms underlying generation of coordinated behavior within the TIDA population remains to be investigated.

Neurons can code information through changes in firing frequency as well as in firing pattern. We investigated whether
A

B
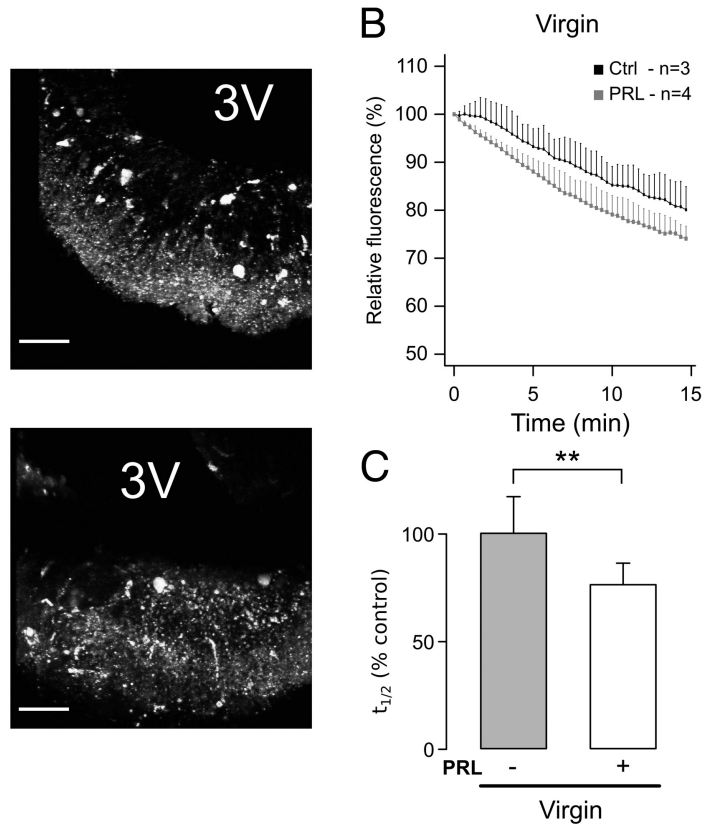

$\mathrm{D}$
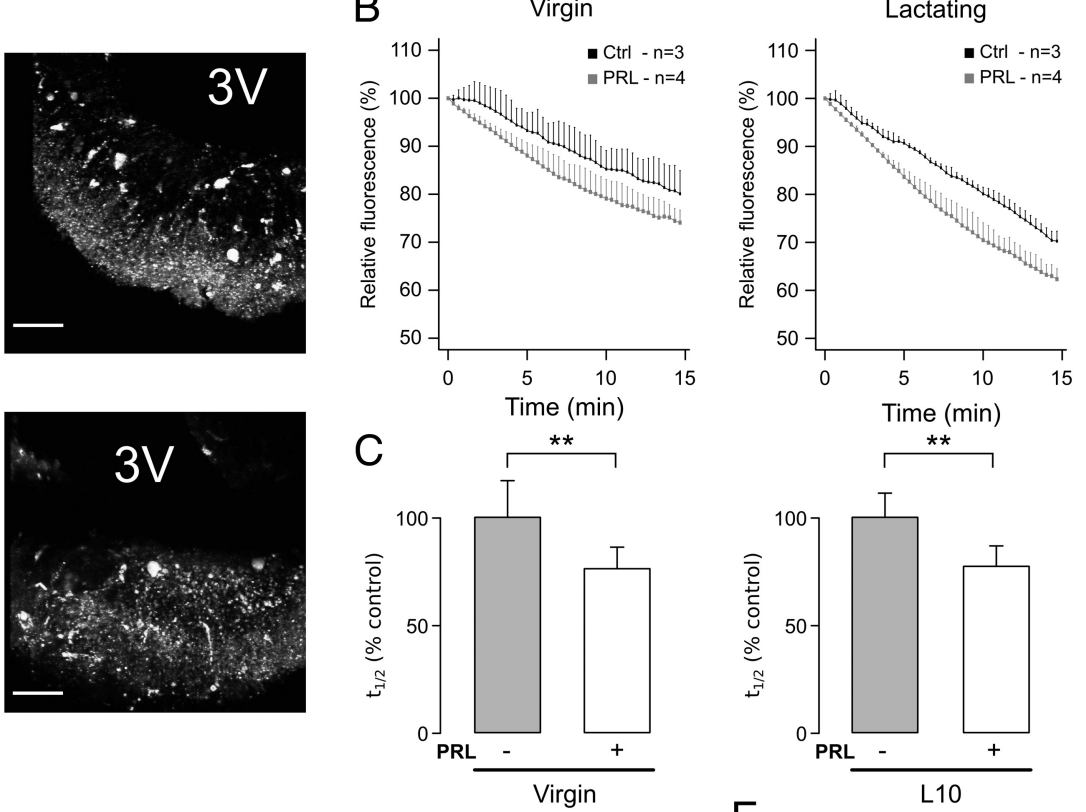

E
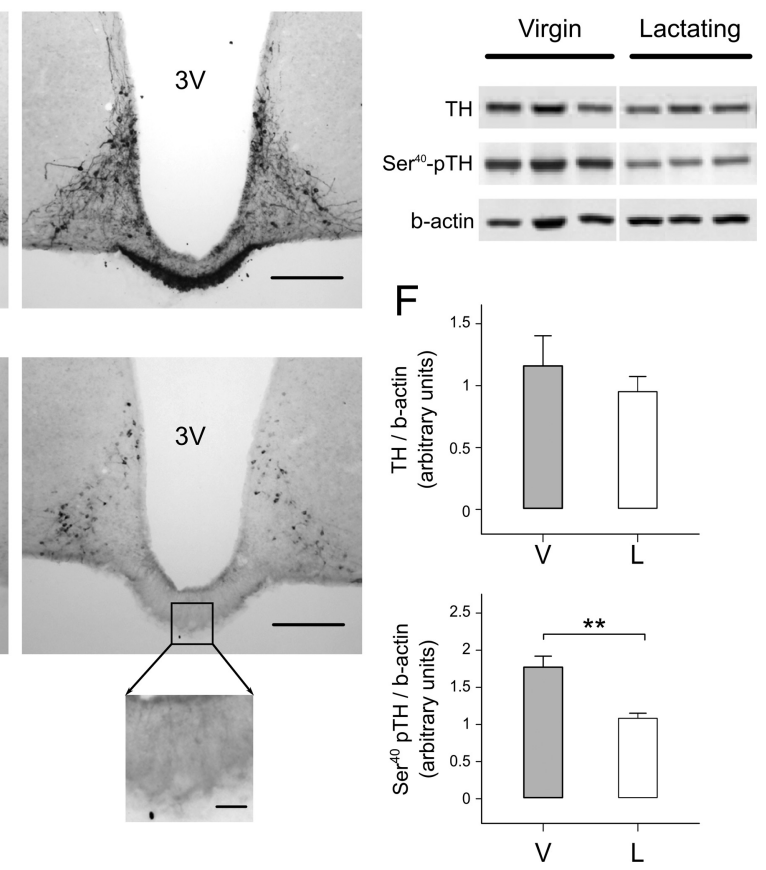

Figure 5. Conservation of DA secretory apparatus coupled with a loss of TH phosphorylation during lactation. A, Projections of $z$-stacks of coronal brain slices from a virgin (top) or lactating (bottom) female, after incubation in FFN-511. Staining is mostly confined to the ME, indicating that the VMAT2 transporter system is active in both situations (3V, third ventricle). $\boldsymbol{B}$, FFN-511 destaining in control (Ctrl) conditions (black line) or when brains were treated with $500 \mathrm{ng} / \mathrm{ml}$ PRL (gray line). Left shows mean relative fluorescence in virgin females. Right shows mean relative fluorescence in lactating females (error bars represent SD). Destaining curves are different from their relative control as are the two control curves (in both cases, $p<0.01$, mixed-effect model ANOVA). C, Bar plot showing the half-times of exponential fit of the FFN-511 destaining curves. Values were normalized to the control in each group [error bars represent $S D_{;}^{* * *} p<0.01$ vs control, the two groups (virgin and L10) are not different from each other, $p>0.05$, two-way ANOVA]. $D$, Top, Representative sections showing TH immunoreactivity in the Arc/ME region in virgin (left; $n=6$ ) and lactating (right; $n=5$ ) females. Bottom, Representative sections showing Ser ${ }^{40}$-phosphorylated TH immunoreactivity in the Arc/ME region in virgin (left; $n=6$ ) and lactating (right; $n=5$ ) females. There is a strong decrease in the phosphorylated TH staining in the ME of lactating animals. Insets show a detail of the ME area. $\boldsymbol{E}$, Representative Western blot for TH and $\mathrm{Ser}^{40}$ phosphorylated TH content in the ME/arcuate region of virgin and lactating animals $(n=5)$. $\boldsymbol{F}$, Densitometric quantification of the Western blot analysis (top, total TH; bottom, Ser ${ }^{40}$ phosphorylated TH). The two groups are not significantly different for the amount of TH ( $p>$ $0.05, t$ test) but are different for the amount of Ser ${ }^{40}$ phospho-TH ( $p<0.01, t$ test). 
firing patterns could play a role in the generation the TIDA output. Experimental and simulated data indicate bursting as central for rhytmogenesis (Sherman, 2001; Bressloff and Coombes, 2005; Wang, 2010) and as the most efficient way to secrete neurotransmitters in various neuronal populations (Gonon, 1988; Brown and Bourque, 2006; Aponte et al., 2011). This modality of firing may help synchronizing the system to increase the efficiency of DA secretion (Lyons et al., 2010). Our data show no statistical difference in the proportions of different firing patterns between virgin and lactating animals, indicating that the plasticity in their output is not a direct derivation of a modulation of firing patterns. These appear to be strongly typed in TIDA and resilient to changes resulting from both long-term and acute stimuli because PRL only affected firing frequency and not pattern. However, a trend toward a reduction in bursting TIDA neurons is seen during lactation. Although this was not statistically significant, possibly because of the small proportion of bursting neurons, we cannot at present exclude that it may have some biological role.

\section{Lactation as a state of altered TIDA output}

During lactation, the output of TIDA neurons undergoes profound changes, as demonstrated by the massive decrease in the DA content of the ME (Nagy et al., 1998) and our data showing marked reduction in detectable DA release.

To support this point, we show that $\mathrm{D}_{2}$ antagonists increase plasma PRL levels in virgin animals by releasing the inhibitory tone on the pituitary (Mueller et al., 1976; Russell et al., 2000; Anderson et al., 2008; Hodson et al., 2012). During lactation, lactotrophs continue to express $\mathrm{D}_{2}$ receptors (Pazos et al., 1985), and the pituitary remains sensitive to DA receptor agonists ( $\mathrm{Li}$ et al., 1999).We show that treatment with $\mathrm{D}_{2}$ antagonists did not generate a significant increase in PRL levels during lactation, confirming that the endogenous inhibitory DA tone is strongly reduced.

We then investigated whether this decrease was reflecting changes in electrophysiological properties of TIDA neurons. No difference was found between the basal activity of TIDA neurons from virgin and lactating animals. Furthermore, electrical responses to PRL were retained during lactation. These data are consistent with the persistence of PRL-R expression during lactation (Kokay and Grattan, 2005) but do not explain the reduction in DA secretion at this time. Although basal levels of phosphorylated signal transducer and activator of transcription 5 (STAT5) are elevated in TIDA during lactation, acute PRLmediated activation of STAT5 is significantly reduced, in part as a result of increased production of SOCS (suppressor of cytokine signaling) proteins (Anderson et al., 2006), which inhibit STAT5 (Hennighausen and Robinson, 2008). Hence, during lactation, intracellular pathways induced by activation of PRL-R are altered, whereas the electrical response to PRL remains unchanged. A recent report has investigated the mechanism of action for this response, revealing that PRL-induced currents are constituted of different components, likely to be activated in response to different intracellular pathways (Lyons et al., 2012). The exact link between PRL-R and electrical activity remains to be elucidated.

Finally, our results highlight TH as a key player in TIDA plasticity during lactation. TH phosphorylation at several Ser residues is the primary mechanism responsible for regulation of DA production. Phosphorylation at $\mathrm{Ser}^{40}$ is central to activate the enzyme (Zigmond et al., 1989; Dunkley et al., 2004). In the rat, local dephosphorylation of TH in the ME is involved in sucklinginduced PRL surges (Fehér et al., 2010), and we observed a marked decrease in phosphorylated $\mathrm{Ser}^{40}$ at the level of the ME during lactation. Therefore, reduced phosphorylation of $\mathrm{TH}$, possibly alongside a decrease in TH mRNA levels (Wang et al., 1993; Li et al., 1999), could explain the absence of secretable DA. This may result from uncoupling of the PRL-R from its cognate Janus kinase/STAT intracellular signaling pathway (Anderson et al., 2006), responsible for phosphorylation of $\mathrm{TH}$ in virgins (Ma et al., 2005).

\section{Conservation of the PRL response: a means of reversibility?}

Secretion of a neurotransmitter requires the establishment of a series of tightly controlled mechanisms to packaging, secrete, and metabolize it. The decrease of DA levels at lactation did not alter the ability of the DA exocytotic apparatus to secrete, when TIDA neurons were loaded with the fluorescent DA analog FFN-511 (Gubernator et al., 2009). Accumulation of FFN-511 at the ME of lactating mice indicates that DA uptake mechanisms are still present. Moreover, the ability of TIDA to release FFN-511 in response to secretory stimuli demonstrates that the exocytotic apparatus of these neurons is functional and coupled to the electrical activity at the cell body during lactation. The persistence of the DA secretion apparatus, together with the conservation of non-phosphorylated TH expression could allow for a quick return to DA production and secretion when the pups are weaned.

Another captivating hypothesis comes from the observation that increased opioidergic immunoreactivity is seen in the Arc of rodents, almost exclusively confined to TIDA neurons during lactation (Ciofi et al., 1993; Merchenthaler, 1993). Compelling evidence exists for physiological effects of this phenotypic switch from DA to opioids production. In particular, opioids suppress DA turnover in TIDA neurons of lactating animals (Andrews and Grattan, 2003). Activation of $\mu$-opioid receptors has been shown to inhibit the activity of TH in TIDA neurons (Arbogast and Voogt, 1998; Zhang et al., 2004) and alter its phosphorylation in other hypothalamic regions (Núñez et al., 2007). It is tempting to speculate that the conservation of the electrical response to PRL could induce the secretion of opioids to further inhibit the TIDA system. This switch would allow TIDA neurons to be able to process the same stimulus (PRL) in a different manner depending on the physiological status of the animal, resulting in profoundly different types of output.

In summary, we have shown that, during lactation, TIDA neurons are not an inactive, silent player in the PRL axis but rather display remarkable plasticity to remain functional and capable of integrating PRL feedback.

\section{Notes}

Supplemental material for this article is available at http://www.igf.cnrs. fr/spip.php?article568. Controls of amperometric recordings. This material has not been peer reviewed.

\section{References}

Anderson GM, Beijer P, Bang AS, Fenwick MA, Bunn SJ, Grattan DR (2006) Suppression of prolactin-induced signal transducer and activator of transcription 5b signaling and induction of suppressors of cytokine signaling messenger ribonucleic acid in the hypothalamic arcuate nucleus of the rat during late pregnancy and lactation. Endocrinology 147:4996-5005. CrossRef Medline

Anderson GM, Kieser DC, Steyn FJ, Grattan DR (2008) Hypothalamic prolactin receptor messenger ribonucleic acid levels, prolactin signaling, and hyperprolactinemic inhibition of pulsatile luteinizing hormone secretion are dependent on estradiol. Endocrinology 149:1562-1570. CrossRef Medline

Andrews ZB (2005) Neuroendocrine regulation of prolactin secretion dur- 
ing late pregnancy: easing the transition into lactation. J Neuroendocrinol 17:466-473. CrossRef Medline

Andrews ZB, Grattan DR (2003) Opioid receptor subtypes involved in the regulation of prolactin secretion during pregnancy and lactation. J Neuroendocrinol 15:227-236. CrossRef Medline

Aponte Y, Atasoy D, Sternson SM (2011) AGRP neurons are sufficient to orchestrate feeding behavior rapidly and without training. Nat Neurosci 14:351-355. CrossRef Medline

Arbogast LA, Voogt JL (1996) The responsiveness of tuberoinfundibular dopaminergic neurons to prolactin feedback is diminished between early lactation and midlactation in the rat. Endocrinology 137:47-54. CrossRef Medline

Arbogast LA, Voogt JL (1998) Endogenous opioid peptides contribute to suckling-induced prolactin release by suppressing tyrosine hydroxylase activity and messenger ribonucleic acid levels in tuberoinfundibular dopaminergic neurons. Endocrinology 139:2857-2862. CrossRef Medline

Baccam N, Alonso G, Costecalde T, Fontanaud P, Molino F, Robinson IC, Mollard P, Méry PF (2007) Dual-level afferent control of growth hormone-releasing hormone (GHRH) neurons in GHRH-green fluorescent protein transgenic mice. J Neurosci 27:1631-1641. CrossRef Medline

Ben-Jonathan N (1980) Catecholamines and pituitary prolactin release. J Reprod Fertil 58:501-512. CrossRef Medline

Ben-Jonathan N (1985) Dopamine: a prolactin-inhibiting hormone. Endocr Rev 6:564-589. CrossRef Medline

Ben-Jonathan N, Oliver C, Weiner HJ, Mical RS, Porter JC (1977) Dopamine in hypophysial portal plasma of the rat during the estrous cycle and throughout pregnancy. Endocrinology 100:452-458. CrossRef Medline

Björklund A, Moore RY, Nobin A, Stenevi U (1973) The organization of tubero-hypophyseal and reticulo-infundibular catecholamine neuron systems in the rat brain. Brain Res 51:171-191. CrossRef Medline

Bole-Feysot C, Goffin V, Edery M, Binart N, Kelly PA (1998) Prolactin (PRL) and its receptor: actions, signal transduction pathways and phenotypes observed in PRL receptor knockout mice. Endocr Rev 19:225-268. CrossRef Medline

Bressloff PC, Coombes S (2005) Bursting: the genesis of rhythm in the nervous system. Singapore: World Scientific Publishing Company.

Bridges RS, DiBiase R, Loundes DD, Doherty PC (1985) Prolactin stimulation of maternal behavior in female rats. Science 227:782-784. CrossRef Medline

Brown CH, Bourque CW (2006) Mechanisms of rhythmogenesis: insights from hypothalamic vasopressin neurons. Trends Neurosci 29:108-115. CrossRef Medline

Ciofi P, Crowley WR, Pillez A, Schmued LL, Tramu G, Mazzuca M (1993) Plasticity in expression of immunoreactivity for neuropeptide $\mathrm{Y}$, enkephalins and neurotensin in the hypothalamic tubero-infundibular dopaminergic system during lactation in mice. J Neuroendocrinol 5:599-602. CrossRef Medline

Demarest KT, McKay DW, Riegle GD, Moore KE (1983) Biochemical indices of tuberoinfundibular dopaminergic neuronal activity during lactation: a lack of response to prolactin. Neuroendocrinology 36:130-137. CrossRef Medline

Dunkley PR, Bobrovskaya L, Graham ME, von Nagy-Felsobuki EI, Dickson PW (2004) Tyrosine hydroxylase phosphorylation: regulation and consequences. J Neurochem 91:1025-1043. CrossRef Medline

Erickson JD, Varoqui H (2000) Molecular analysis of vesicular amine transporter function and targeting to secretory organelles. FASEB J 14:24502458. CrossRef Medline

Fehér P, Oláh M, Bodnár I, Hechtl D, Bácskay I, Juhász B, Nagy GM, Vecsernyés M (2010) Dephosphorylation/inactivation of tyrosine hydroxylase at the median eminence of the hypothalamus is required for suckling-induced prolactin and adrenocorticotrop hormone responses. Brain Res Bull 82:141-145. CrossRef Medline

Freeman ME, Kanyicska B, Lerant A, Nagy G (2000) Prolactin: structure, function, and regulation of secretion. Physiol Rev 80:1523-1631. Medline

Gonon FG (1988) Nonlinear relationship between impulse flow and dopamine released by rat midbrain dopaminergic neurons as studied by in vivo electrochemistry. Neuroscience 24:19-28. CrossRef Medline

Gonon F, Buda M, Cespuglio R, Jouvet M, Pujol JF (1981) Voltammetry in the striatum of chronic freely moving rats: detection of catechols and ascorbic acid. Brain Res 223:69-80. CrossRef Medline

Grattan DR, Kokay IC (2008) Prolactin: a pleiotropic neuroendocrine hormone. J Neuroendocrinol 20:752-763. CrossRef Medline
Gubernator NG, Zhang H, Staal RG, Mosharov EV, Pereira DB, Yue M, Balsanek V, Vadola PA, Mukherjee B, Edwards RH, Sulzer D, Sames D (2009) Fluorescent false neurotransmitters visualize dopamine release from individual presynaptic terminals. Science 324:1441-1444. CrossRef Medline

Hennighausen L, Robinson GW (2008) Interpretation of cytokine signaling through the transcription factors STAT5A and STAT5B. Genes Dev 22: 711-721. CrossRef Medline

Herbison AE (2006) Physiology of the GnRH neuronal network. In: Knobil and Neill's physiology of reproduction. San Diego: Academic.

Hodson DJ, Schaeffer M, Roman ò N, Fontanaud P, Lafont C, Birkenstock J, Molino F, Christian H, Lockey J, Carmignac D, Fernandez-Fuente M, Le Tissier P, Mollard P (2012) Existence of long-lasting experiencedependent plasticity in endocrine cell networks. Nat Commun 3:605. CrossRef Medline

Hong S, Ratté S, Prescott SA, De Schutter E (2012) Single neuron firing properties impact correlation-based population coding. J Neurosci 32:1413-1428. CrossRef Medline

Kokay IC, Grattan DR (2005) Expression of mRNA for prolactin receptor (long form) in dopamine and pro-opiomelanocortin neurones in the arcuate nucleus of non-pregnant and lactating rats. J Neuroendocrinol 17:827-835. CrossRef Medline

Kreitzer AC, Malenka RC (2007) Endocannabinoid-mediated rescue of striatal LTD and motor deficits in Parkinson's disease models. Nature 445: 643-647. CrossRef Medline

Krsmanovic LZ, Hu L, Leung PK, Feng H, Catt KJ (2010) Pulsatile GnRH secretion: roles of $\mathrm{G}$ protein-coupled receptors, second messengers and ion channels. Mol Cell Endocrinol 314:158-163. CrossRef Medline

Larsen CM, Grattan DR (2010) Prolactin-induced mitogenesis in the subventricular zone of the maternal brain during early pregnancy is essential for normal postpartum behavioral responses in the mother. Endocrinology 151:3805-3814. CrossRef Medline

Leng G, Brown CH, Russell JA (1999) Physiological pathways regulating the activity of magnocellular neurosecretory cells. Prog Neurobiol 57:625655. CrossRef Medline

Leng G, Moos FC, Armstrong WE (2010) The adaptive brain: Glenn Hatton and the supraoptic nucleus. J Neuroendocrinol 22:318-329. CrossRef Medline

Lerant A, Kanyicska B, Freeman ME (2001) Nuclear translocation of STAT5 and increased expression of Fos related antigens (FRAs) in hypothalamic dopaminergic neurons after prolactin administration. Brain Res 904: 259-269. CrossRef Medline

Li C, Chen P, Smith MS (1999) Neuropeptide Y and tuberoinfundibular dopamine activities are altered during lactation: role of prolactin. Endocrinology 140:118-123. CrossRef Medline

Lucas BK, Ormandy CJ, Binart N, Bridges RS, Kelly PA (1998) Null mutation of the prolactin receptor gene produces a defect in maternal behavior. Endocrinology 139:4102-4107. CrossRef Medline

Lyons DJ, Horjales-Araujo E, Broberger C (2010) Synchronized network oscillations in rat tuberoinfundibular dopamine neurons: switch to tonic discharge by thyrotropin-releasing hormone. Neuron 65:217-229. CrossRef Medline

Lyons DJ, Hellysaz A, Broberger C (2012) Prolactin regulates tuberoinfundibular dopamine neuron discharge pattern: novel feedback control mechanisms in the lactotrophic axis. J Neurosci 32:8074-8083. CrossRef Medline

Ma FY, Anderson GM, Gunn TD, Goffin V, Grattan DR, Bunn SJ (2005) Prolactin specifically activates signal transducer and activator of transcription $5 \mathrm{~b}$ in neuroendocrine dopaminergic neurons. Endocrinology 146:5112-5119. CrossRef Medline

MacLeod RM, Fontham EH, Lehmeyer JE (1970) Prolactin and growth hormone production as influenced by catecholamines and agents that affect brain catecholamines. Neuroendocrinology 6:283-294. CrossRef Medline

McGuinness L, Magoulas C, Sesay AK, Mathers K, Carmignac D, Manneville JB, Christian H, Phillips JA 3rd, Robinson IC (2003) Autosomal dominant growth hormone deficiency disrupts secretory vesicles in vitro and in vivo in transgenic mice. Endocrinology 144:720-731. CrossRef Medline

Merchenthaler I (1993) Induction of enkephalin in tuberoinfundibular dopaminergic neurons during lactation. Endocrinology 133:2645-2651. CrossRef Medline 
Moore KE (1987) Interactions between prolactin and dopaminergic neurons. Biol Reprod 36:47-58. CrossRef Medline

Mueller GP, Simpkins J, Meites J, Moore KE (1976) Differential effects of dopamine agonists and haloperidol on release of prolactin, thyroid stimulating hormone, growth hormone and luteinizing hormone in rats. Neuroendocrinology 20:121-135. CrossRef Medline

Nagy GM, DeMaria JE, Freeman ME (1998) Changes in the local metabolism of dopamine in the anterior and neural lobes but not in the intermediate lobe of the pituitary gland during nursing. Brain Res 790:315-317. CrossRef Medline

Nowak LG, Azouz R, Sanchez-Vives MV, Gray CM, McCormick DA (2003) Electrophysiological classes of cat primary visual cortical neurons in vivo as revealed by quantitative analyses. J Neurophysiol 89:1541-1566. Medline

Núñez C, Laorden ML, Milanés MV (2007) Regulation of serine (Ser)-31 and Ser40 tyrosine hydroxylase phosphorylation during morphine withdrawal in the hypothalamic paraventricular nucleus and nucleus tractus solitarius-A2 cell group: role of ERK1/2. Endocrinology 148:5780-5793. CrossRef Medline

Pazos A, Stoeckel ME, Hindelang C, Palacios JM (1985) Autoradiographic studies on dopamine D2 receptors in rat pituitary: Influence of hormonal states. Neurosci Lett 59:1-7. CrossRef Medline

Pike CM, Grabner CP, Harkins AB (2009) Fabrication of amperometric electrodes. J Vis Exp pii:1040. CrossRef

Reymond MJ, Porter JC (1985) Involvement of hypothalamic dopamine in the regulation of prolactin secretion. Horm Res 22:142-152. CrossRef Medline

Russell SH, Kim MS, Small CJ, Abbott CR, Morgan DG, Taheri S, Murphy KG, Todd JF, Ghatei MA, Bloom SR (2000) Central administration of orexin A suppresses basal and domperidone stimulated plasma prolactin. J Neuroendocrinol 12:1213-1218. CrossRef Medline

Shen W, Flajolet M, Greengard P, Surmeier DJ (2008) Dichotomous dopaminergic control of striatal synaptic plasticity. Science 321:848-851. CrossRef Medline
Sherman SM (2001) Tonic and burst firing: dual modes of thalamocortical relay. Trends Neurosci 24:122-126. CrossRef Medline

Shingo T, Gregg C, Enwere E, Fujikawa H, Hassam R, Geary C, Cross JC, Weiss S (2003) Pregnancy-stimulated neurogenesis in the adult female forebrain mediated by prolactin. Science 299:117-120. CrossRef Medline

Shinomoto S, Shima K, Tanji J (2003) Differences in spiking patterns among cortical neurons. Neural Comput 15:2823-2842. CrossRef Medline

Srinivas S, Watanabe T, Lin CS, William CM, Tanabe Y, Jessell TM, Costantini F (2001) Cre reporter strains produced by targeted insertion of EYFP and ECFP into the ROSA26 locus. BMC Dev Biol 1:4. CrossRef Medline

Surmeier DJ, Plotkin J, Shen W (2009) Dopamine and synaptic plasticity in dorsal striatal circuits controlling action selection. Curr Opin Neurobiol 19:621-628. CrossRef Medline

Terasawa E, Schanhofer WK, Keen KL, Luchansky L (1999) Intracellular $\mathrm{Ca}^{2+}$ oscillations in luteinizing hormone-releasing hormone neurons derived from the embryonic olfactory placode of the rhesus monkey. J Neurosci 19:5898-5909. Medline

Turiault M, Parnaudeau S, Milet A, Parlato R, Rouzeau JD, Lazar M, Tronche F (2007) Analysis of dopamine transporter gene expression patterngeneration of DAT-iCre transgenic mice. FEBS J 274:3568-3577. CrossRef Medline

Wang HJ, Hoffman GE, Smith MS (1993) Suppressed tyrosine hydroxylase gene expression in the tuberoinfundibular dopaminergic system during lactation. Endocrinology 133:1657-1663. CrossRef Medline

Wang XJ (2010) Neurophysiological and computational principles of cortical rhythms in cognition. Physiol Rev 90:1195-1268. CrossRef Medline

Zhang B, Hou Y, Voogt JL (2004) Effects of opioid antagonism on prolactin secretion and c-Fos/TH expression during lactation in rats. Endocrine 25:131-136. CrossRef Medline

Zigmond RE, Schwarzschild MA, Rittenhouse AR (1989) Acute regulation of tyrosine hydroxylase by nerve activity and by neurotransmitters via phosphorylation. Annu Rev Neurosci 12:415-461. CrossRef Medline 